\title{
Premature opening of aortic valve in severe aortic regurgitation
}

\author{
Antony Page and Clive Layton \\ From the Cardiac Department, The London Hospital, London
}

Premature opening of the aortic valve in late diastole has been demonstrated by echocardiography in a patient with severe aortic regurgitation. Valve opening coincided with the end of the diastolic murmur and equalization of aortic and left ventricular diastolic pressures.

Echocardiography of the aortic valve in severe aortic reflux may, therefore, provide valuable information about the underlying haemodynamic disturbance.

The haemodynamic consequences of aortic regurgitation are dependent not only on the extent of the anatomical disruption of the aortic valve but also on factors such as the peripheral vascular resistance and the duration of diastole (Rees et al., 1964). With severe reflux, premature closure of the mitral valve has been noted (Wright, Toscano-Barboza, and Brandenburg, 1956): this phenomenon has been confirmed by echocardiography (Pridie, Benham, and Oakley, 197r). More recently it has also become possible to examine the aortic valve using reflected ultrasound, and characteristic features can be recognized in most patients with aortic regurgitation (Feizi, Symons, and Yacoub, 1974). During the routine investigation of severe aortic regurgitation in a 24-year-old man with Marfan's syndrome a previously unreported echocardiographic finding was apparent.

\section{Case report}

A 24-year-old man was admitted to hospital after a road accident during which he sustained a minor head injury. He complained of no other symptoms except a number of brief episodes of palpitation over the preceding six months. On examination the signs of Marfan's syndrome were apparent. Height was $186 \mathrm{~cm}$ and arm span $198 \mathrm{~cm}$. Arachnodactyly and a high arched palate were noted and also bilateral subluxation of the lenses though visual acuity was normal. The venous pressure was not raised but the carotid pulse was collapsing in type and the apical impulse hyperdynamic. At the left sternal edge a diastolic thrill was palpable and auscultation confirmed an early diastolic murmur. The first heart sound at the apex was soft and was followed by an ejection systolic murmur of moderate intensity. The arterial pressure was $110 / 40 \mathrm{mmHg}$ (14.6/5.3 $\mathrm{kPa}$ ) in both arms.

The electrocardiogram confirmed the presence of left ventricular hypertrophy and, at times, a sinus bradycardia of 56 beats a minute. The chest radiograph showed considerable cardiac enlargement, with prominence of the ascending aorta suggesting the presence of an aortic aneurysm. Pulmonary venous congestion appeared slight.

\section{Echocardiography}

Echocardiographic studies were made of mitral and aortic valve movements and of left ventricular dimensions using a Smith Kline Ekoline 20 ultrasound recorder with a $2 \mathrm{~cm}$ diameter focused transducer using $2.25 \mathrm{MHz}$ and a repetition rate of 1000 pulses a second. Recordings were made with a Cambridge multichannel photographic recorder and an echo interface module.

The left ventricular dimension at end-systole was $6.3 \mathrm{~cm}$ and at end-diastole was $8.1 \mathrm{~cm}$. Septal movement appeared normal. Satisfactory echoes were obtained from both mitral valve cusps (Fig. I). The anterior and posterior cusps showed large amplitude oscillations at a frequency of approximately $50 \mathrm{~Hz}$ in the early part of diastole. Closure of the valve occurred midway through diastole with complete apposition of the cusps, the valve then remained closed during atrial and ventricular systole. The total amplitude of movement of the anterior cusp was $3.0 \mathrm{~cm}$ and the diastolic closure rate $70 \mathrm{~mm} / \mathrm{s}$. The aortic echogram showed diastolic oscillation of both the visualized cusps similar to that seen with the mitral valve (Fig. 2A). Opening of the aortic valve was premature, occurring just before the QRS complex of the electrocardiogram. During periods of slower heart rate 


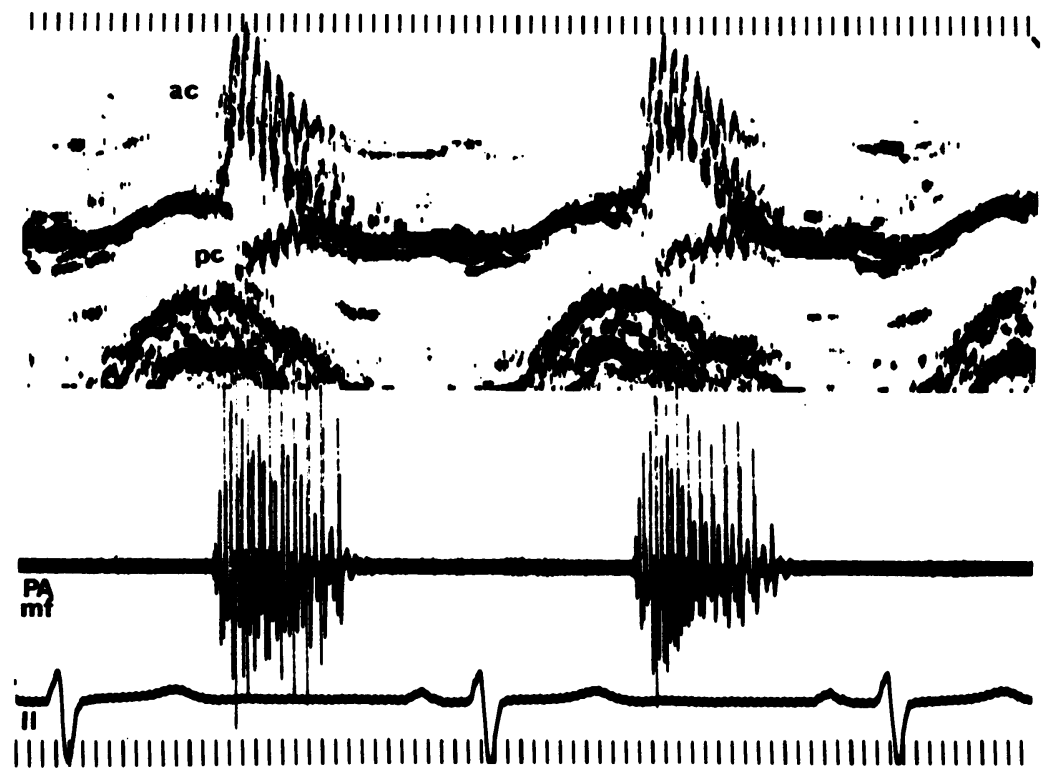

FIG. I Mitral echogram with simultaneous electrocardiogram and phonocardiogram. $P A=$ pulmonary area; $m f=$ medium frequency; ac = anterior cusp; $p c=$ posterior cusp.

the separation of the cusps was more obviously premature, occurring in late diastole before the $P$ wave of the electrocardiogram (Fig. 2B). The valve then remained open until rapid closure at the end of systole. The duration of the murmur corresponded to the duration of aortic valve closure in diastole. When premature opening of the valve occurred the murmur ended with separation of the cusps (Fig. 2). The aortic root diameter measured immediately above the mitral valve was $48 \mathrm{~mm}$.

\section{Haemodynamic and angiographic findings}

The haemodynamic data are summarized in the Table. During diastole there was a rapid rise in the left ventricular diastolic pressure which exceeded the indirect left atrial pressure midway through diastole. Equalization of the ventricular and aortic pressures occurred in late diastole; during periods of bradycardia ( 60 beats a minute) and in the compensatory pause following a ventricular extrasystole, equalization of pressures preceded the $P$ wave of the electrocardiogram. There was no systolic pressure gradient across the aortic valve. Left ventriculography was performed in the right anterior oblique projection. The ventricle was grossly dilated but there was no mitral regurgitation. Left ventricular volumes were measured using the single plane method of Greene et al. (1967). The end-diastolic volume was $680 \mathrm{ml}$, end-systolic volume $403 \mathrm{ml}$, stroke volume $277 \mathrm{ml}$, and ejection fraction $0.4 \mathrm{I}$. Aortography was performed on cine film in the left anterior oblique projection and also on biplane roll film. Severe aortic regurgitation was observed, with a large aneurysm of the ascending aorta extending from the valve ring to the proximal part of the aortic arch.
The aneurysm tapered just proximal to the origin of the innominate artery. The aortic root diameter measured by angiography was $50 \mathrm{~mm}$ and the aortic diameter at its maximum point was $67 \mathrm{~mm}$.

\section{Discussion}

Echocardiographic study of aortic valve movement is being used increasingly in the assessment of patients with aortic valve disease. The technique has become more reliable with the use of strip-chart recorders which allow satisfactory records to be obtained in over 80 per cent of patients studied (Feizi et al., 1974). The two main features of aortic regurgitation identified by ultrasound have been diastolic separation of the cusps and an increase in the diameter of the aortic root (Feizi et al., 1974). Premature opening of the aortic valve has not previously been reported. The features of aortic reflux with respect to the mitral echogram are premature closure of the mitral valve, particularly in severe aortic regurgitation of acute onset, and diastolic oscillation of the anterior cusp (Pridie et al., 1971). Both of these features were present in the case described with obvious oscillation of the posterior cusp also. The early closure of the mitral valve is related to the rapid rise in diastolic pressure in the left ventricle which may exceed left atrial pressure in mid-diastole.

Late diastolic opening of the aortic valve is a new finding that assists in the interpretation of the haemodynamic effects of severe aortic regurgitation. 

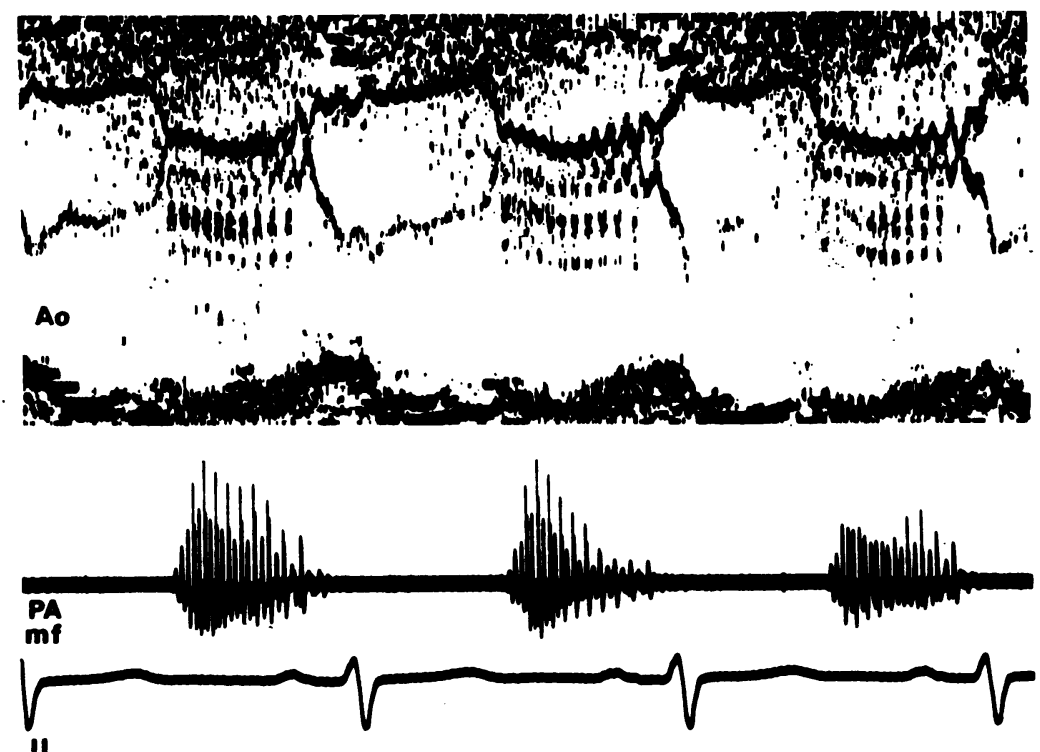

IIIIIIIIIIIIIIIIIIIIIIIIIIIIIIIIIIIIIIIIIIIIIIIIIIIIIIIIIIIIIIIIIIIIII $A$
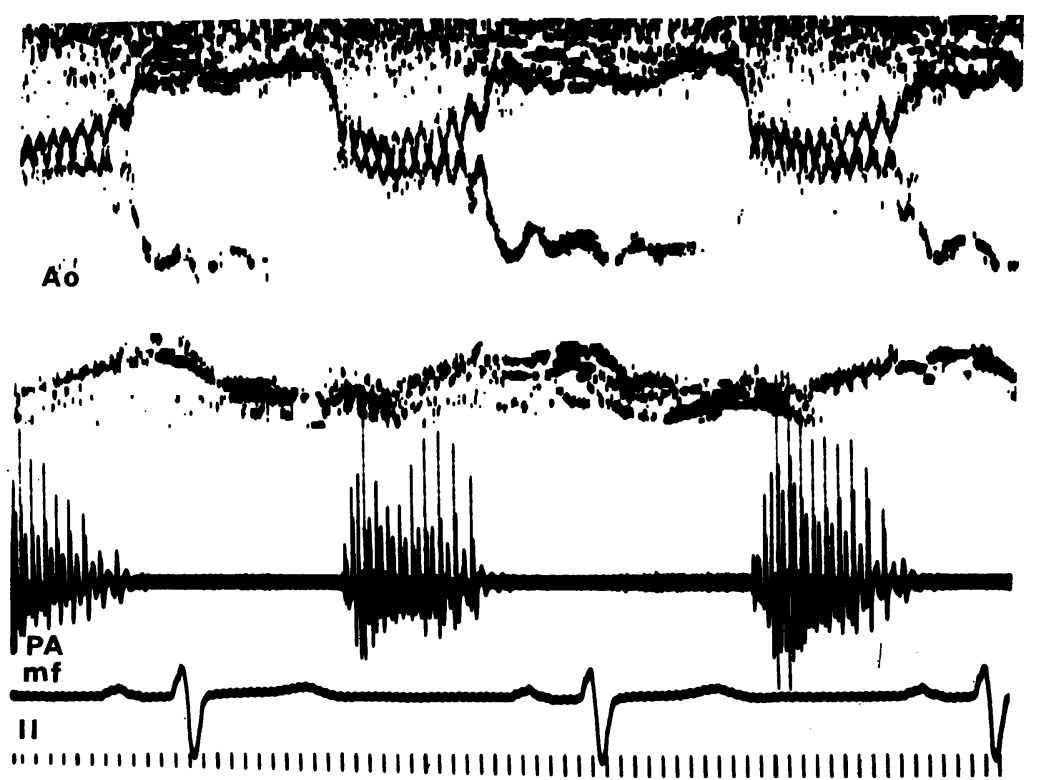

$B$

FIG. 2 A) Aortic echogram with simultaneous electrocardiogram and phonocardiogram. Ao= aorta. B) Aortic echogram at slower heart rate. 


\section{TABLE Haemodynamic findings}

\begin{tabular}{ll}
\hline Site & Pressure $(\mathrm{kPa})$ \\
\hline Right atrium & $(1.9)$ \\
Right ventricle & $6.7 / 0$ \\
Pulmonary artery & $6.7 / 2.4 \quad(3.3)$ \\
Indirect left atrium & 2.7 \\
Left ventricle & $14.6 / 0$ \\
& End-diastolic 6.7 \\
Aorta & $14.6 / 6.7 \quad(9.3)$ \\
\hline
\end{tabular}

Conversion factor from SI units to Traditional units: I kPa $\approx 7.5$ $\mathrm{mmHg}$. Mean pressures in parentheses.

In most cases of aortic reflux the two most obvious pressure changes are a fall in the aortic diastolic pressure and a rise in left ventricular end-diastolic pressure. The former is determined partly by the peripheral resistance and partly by the extent of the reflux into the left ventricle. The determinants of the ventricular end-diastolic pressure include the change in volume during diastole, the end-systolic pressure and volume, and ventricular wall stiffness. Equalization of the diastolic pressures in the aorta and left ventricle is uncommon even in the presence of severe degrees of aortic reflux (Rees et al., I964), but occurred in this case and corresponded in timing to the premature opening of the aortic valve.
At this point also the murmur ended, suggesting that no further regurgitant flow took place.

The echocardiographic finding of premature opening of the aortic valve in late diastole permits the recognition of pressure equalization between the left ventricle and aorta by a non-invasive technique. This provides a clearer understanding of the underlying haemodynamic disturbance.

\section{References}

Feizi, O., Symons, C., and Yacoub, M. (1974). Echocardiography of the aortic valve. British Heart fournal, 36, 34I.

Greene, D. G., Carlisle, R., Grant, C., and Bunnell, I. L. (1967). Estimation of left ventricular volume by one-plane cineangiography. Circulation, 35, 6r.

Pridie, R. B., Benham, R., and Oakley, C. M. (I97I). Echocardiography of the mitral valve in aortic valve disease. British Heart fournal, 33, 296.

Rees, J. R., Epstein, E. J., Criley, J. M., and Ross, R. S. (1964). Haemodynamic effects of severe aortic regurgitation. British Heart fournal, 26, 412.

Wright, J. L., Toscano-Barboza, E., and Brandenburg, R. O. (1956). Left ventricular and aortic pressure pulses in aortic valvular disease. Proceedings of the Staff Meetings of the Mayo Clinic, 31, 120.

Requests for reprints to Dr. Clive Layton, Cardiac Department, The London Hospital, Whitechapel, London EI IBB. 